\title{
Posterior Superior Alveoler Arter Konumunun Cinsiyet ile Illişkisi: Retrospektif Analiz
}

\author{
Ahmet Murat ÖZER ${ }^{*}$, Ayşe BULUT***
}

\section{$\ddot{O} z$}

Amaç: Maksiller sinüs anatomisi hakkında yeterli bilgi, perioperatif veya postoperatif komplikasyonlardan kaçınmak için gereklidir. Bu çalışmanın amacı, konik ışınlı bilgisayarlı tomografi (KIBT) ile posterior superior alveolar arterin (PSAA) prevalansını, çapını, yerini ve maksiller sinüs tabanı ve alveolar kret ile ilişkisini belirlemektir.

Yöntem: Konik Işınlı Bilgisayarlı Tomografi görüntülemesi yapılmış 5o hastanın (100 maksiller sinüs) maksiller sinüsteki PSAA konumu ve çapları ile PSAA’nın lateral duvardaki alt noktası ile sinüs tabanı ve kret tepesi arasındaki mesafelerin cinsiyet ile ilişkisi retrospektif olarak değerlendirilmiştir. Tüm veriler SPSS versiyon 22.0 programı kullanılarak analiz edilmiştir. Sonuçlar $\mathrm{p}<0,05$ için istatistiksel olarak anlamlı kabul edilmiştir.

Bulgular: PSAA, KIBT taramalarının \%10o'ünde tespit edilmiştir. Arterin yerleşim yeri ile cinsiyet arasında istatistiksel olarak anlamlı fark bulunmuştur ( $\mathrm{p}=0,005)$. PSAA'nın kadınlarda $\% 56$, erkeklerde ise \%34 oranında sinüs membranının altında yerleştiği saptanmıştır. PSAA'nın lateral sinüs duvarının dış korteksinde yerleşimi ise erkeklerde kadınlara oranla 10 kat daha fazla bulunmuştur. Ortalama PSAA çapı 1,07 mm olarak ölçülmüştür. PSAA'nın alt sınırı ile sinüs tabanı arasında dik olarak ölçülen ortalama mesafe 8,30 $\pm 4,17 \mathrm{~mm}$, oblik olarak ölçülen ortalama mesafe 9,26 $\pm 4,34 \mathrm{~mm}$ idi. PSAA'nın alt sınırı ile kret tepesi arasında dik olarak yapılan ölçümlerdeki ortalama mesafe $16,66 \pm 5,17 \mathrm{~mm}$, oblik olarak ölçülen ortalama mesafe ise $18,36 \pm 4,84 \mathrm{~mm}$ olarak bulunmuştur.

\section{Özgün Araştırma Makalesi (Original Research Article)}

Geliş / Received: 10.03.2021 \& Kabul / Accepted: 31.03.2021

DOI: https://doi.org/10.38079/igusabder.894404.

${ }^{*}$ Dr. Öğr. Üyesi, Kıbrıs Sağlık ve Toplum Bilimleri Üniversitesi, Diş Hekimliği Fakültesi, Güzelyurt, KKTC, E-posta: kstuozer@gmail.com ORCIID https://orcid.org/0000-0003-19502724

** Dr. Öğr. Üyesi, Uluslararası Kıbrıs Üniversitesi, Diş Hekimliği Fakültesi, Lefkoşa, KKTC, E-posta: draysebulut@gmail.com ORCID https://orcid.org/o000-0002-3893-5691 
Sonuç: Bu çalışmadan elde edilen bulgular, PSAA konumu ve PSAA ile maksiller sinüs tabanı arasındaki mesafenin cinsiyete göre farklllık gösterebileceğini düşündürmüştür. Bu yönlerden KIBT'lerin preoperatif değerlendirilmesi tedavi planı ve başarısı açısından oldukça önemlidir.

Anahtar Kelimeler: Konik ışınlı bilgisayarlı tomografi, maksiller sinüs, posterior superior alveoler arter.

\title{
Evaluation of the Relationship Between the Position of Posterior Superior Alveolar Artery and Gender: A Retrospective Analysis
}

\begin{abstract}
Aim: Sufficient knowledge of the maxillary sinus anatomy is essential for avoiding perioperative or postoperative complications. The purpose of this study was to determine the prevalence, diameter, location of the posterior superior alveolar artery (PSAA) and its relationship to the floor of the maxillary sinus and alveolar crest using cone-beam computed tomography (CBCT).

Method: A total of 50 CBCT images (100 maxillary sinuses) were analyzed. The PSAA position and diameters and the distances between the lower border of the PSAA and the maxillary sinus floor and alveolar crest were measured retrospectively in relation to sex. All data were analyzed using SPSS for Windows version 22.0. Results were considered statistically significant for $\mathrm{p}$ $<0,05$.

Results: PSAA was detected in $100 \%$ of CBCT scans. There was a statistically significant difference between the location of the artery and gender $(\mathrm{p}=0,005)$. PSAA was located beneath the sinus membrane in $56 \%$ of women and $34 \%$ of men. It was determined that PSAA is located in the outer cortex of the lateral sinus wall 10 times more in men than in women. The mean diameter of the PSAA was $1,07 \mathrm{~mm}$. The mean distance measured vertically from the inferior border of the PSAA to the sinus floor was $8,30 \pm 4,17 \mathrm{~mm}$, the mean oblique distance was $9,26 \pm 4,34 \mathrm{~mm}$. The mean distance measured vertically from the inferior border of the PSAA to the alveolar crest was $16,66 \pm 5,17 \mathrm{~mm}$, the mean oblique distance was $18,36 \pm 4,84 \mathrm{~mm}$.

Conclusion: The findings from this study suggested that PSAA location and distance between PSAA and maxillary sinus floor may differ by gender. Preoperative evaluation of CBCTs in these aspects is very important in terms of treatment plan and success.
\end{abstract}

Keywords: Cone beam computed tomography, maxillary sinus, posterior superior alveolar artery 


\section{Giriş}

Paranazal hava boşluklarının en büyüğü olan maksiller sinüs, piramit şeklindedir ve maxillanın korpusu içinde bulunur ${ }^{1}$. Maksiller sinüs ve Schneiderian membranın vaskülarizasyonu, maksiller arter tarafından sağlanır. Posterior superior alveolar arter (PSAA) ve infraorbital arter (IOA), lateral sinüs duvarı ve üzerini örten membranı besleyen maksiller arterin pterygopalatin parçasının dallarıdır ${ }^{2-4}$. Her iki arter de maxiller sinus çevresinde birbirleriyle anastomoz yapan extraosseos ve intraosseos dallar verir5.

İmplant uygulamasının başarılı olabilmesi için, uygun kalınlıkta ve kalitede kemik gerekmektedir. Özellikle bu durum, alveolar kemik rezorpsiyonu ve maksiller sinüs boşluğunun pnömatizasyonunu gerektiren posterior maksillada geçerlidir. Sinüs tabanının yükseltilmesi, diş implantlarının başarılı bir şekilde yerleştirilmesi için gerekli dikey yüksekliği arttırmakta öngörülebilir bir cerrahi yöntemdir,7. Lateral duvar sinüs yaklaşımı sırasında; maksiller kemikte oluşabilecek nekroz, membran perforasyonları ve kanama, prosedürle ilişkili komplikasyonlardır ${ }^{8}$. Bu komplikasyonları önleyebilmek için, maksiller sinüsün kanlanması, PSAA'nın alveolar kemikteki konumu ve yüksekliği gibi konularda bilgi sahibi olmak gerekmektedir. PSAA ve IOA’in maksimum çapları sırasıyla 2 mm ve 2,7 mm'ye ulaşabilir ${ }^{9}$. Arterin çapının büyüklüğüne bağlı olarak kanama şiddeti riski de artar. Olası kanama riski nedeniyle, cerrahi uygulamalar sırasında bu damarlar göz önünde bulundurulmalıdır ${ }^{10}$. Bu nedenle, cerrahi uygulamalar öncesinde bölgenin anatomisi dikkatli incelenmelidir.

Sinüs cerrahisi ile ilişkideki anatomik yapıların analizinde konik ışını oldukça faydalıdır ${ }^{11}$. Cerrahi işlemlerde başarı oranını artırmak ve komplikasyonları azaltmak için KIBT, maksiller sinüsün üç boyutlu incelenmesini sağlar. Daha uygun bir cerrahi girişim ve tedavi planlanabilmesinde, maksiller sinüsün anatomik varyasyonları ve maksiller sinüs morfolojisi KIBT ile saptanabilir ${ }^{1,12}$. KIBT ayrıca kemik boyutunu değerlendirmek, spesifik anatomik sınırları tespit etmek ve sinüs patolojilerini saptamak için de kullanılabilir5. Maxiller sinusun anatomik varyasyonları KIBT ile saptanabilir ve maxiller sinus morfolojisi ile PSAA’in yerleşimi belirlenerek daha net bir cerrahi girişim ve tedavi planlanabilir ${ }^{12}$. 
Bu çalışmada, erişkinlerde KIBT’lerin retrospektif olarak incelenmesi ile PSAA'nın çapı, farklı anatomik konumlarının saptanması, PSAA konumunun cinsiyet ile ilişkisi, PSAA ile alveoler kret tepesi ve sinüs tabanı arası mesafelerin belirlenerek cerrahi girişim için uygun planlama yapılabilmesi ve olası komplikasyonların önüne geçilmesi amaçlanmıştır.

\section{Gereç ve Yöntem}

Çalışma, Ocak 2018-Mart 2020 tarihleri arasında özel bir radyoloji merkezine farklı klinik endikasyonlar ile müracaat etmiş olan hastaların, KIBT görüntülemelerinde maksiller sinüslerin retrospektif olarak incelenmesi ile gerçekleştirildi.

Toplamda 25 kadın, 25 erkek (50 erişkin) hastanın (50 sol ve 50 sağ) KIBT görüntülerindeki 100 maksiller sinüsünde PSAA ölçümleri, cihaza ait programla yapıldı ve çalışmaya uygun olarak değerlendirildi.

Çalışmada 25-60 yaş aralığında, kraniofasiyal problemi olmayan hastaların volumetrik tomografileri değerlendirildi. Öykülerinde daha önce maksillofasyal travma öyküsü veya fraktür varlığı, doğumsal yüz asimetrisi veya yarık damak bulunan hastalar, tümörler ile uygun pozisyonlamanın yapılamadığı ve görüntü bulanıklığı olan tomografiler çalışmadan çıkarıldı. Çekilen tomografiler dişli, dişsiz ve kısmi dişli olarak sınıflandırıldı. Ölçümler esas olarak, PSAA'nın lokalizasyonu ve çapını belirlemek, PSAA'nın lateral duvardaki alt sınırı ile sinüs tabanı ve alveoler kret arasındaki mesafeleri ölçmek amacıyla yapıldı. Cinsiyet, çekilen tomografinin hangi tarafa ait olduğu, bölgede diş olup olmadığı, PSAA'nın lokalizasyonu ve çapı kaydedildi. PSAA'nın alt sınırından alveolar krete tepesine ve sinüs tabanına olan mesafe ölçüldü. Tomografi kesitlerinden PSAA'nın maksiller sinüs lateral duvarındaki konumuna göre; lateral sinüs duvarının dış korteksinde (dış), kemik içinde (orta) ve membranın altında (iç) (Şekil 1) olacak şekilde

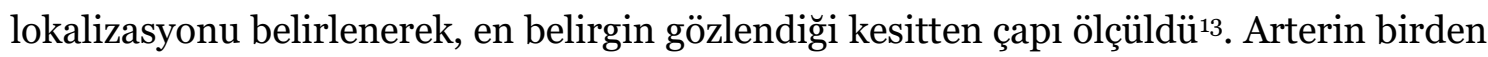
fazla alanda görülmesi ve perioperatif kanamanın ortaya çıkmasında arter çapının önemi dikkate alınarak PSAA'nın en büyük çapı ölçüldü. PSAA çapına göre 2 grup tanımlandı: Grup 1: <1 mm ve Grup 2: 1-2 mm. PSAA'nın lateral duvardaki alt noktası ile sinüs tabanı arasındaki oblik ve izdüşümsel dik mesafeleri ile PSAA'nın lateral duvardaki alt noktası ile alveoler kret tepesi arasındaki oblik ve izdüşümsel dik mesafeleri ölçüldü (Şekil 2). 
Şekil 1. PSAA'nın maksiller sinüs lateral duvarındaki konumu; a) membranın altında (iç) b) kemik içinde (orta) c) lateral sinüs duvarının dış korteksinde (dış)
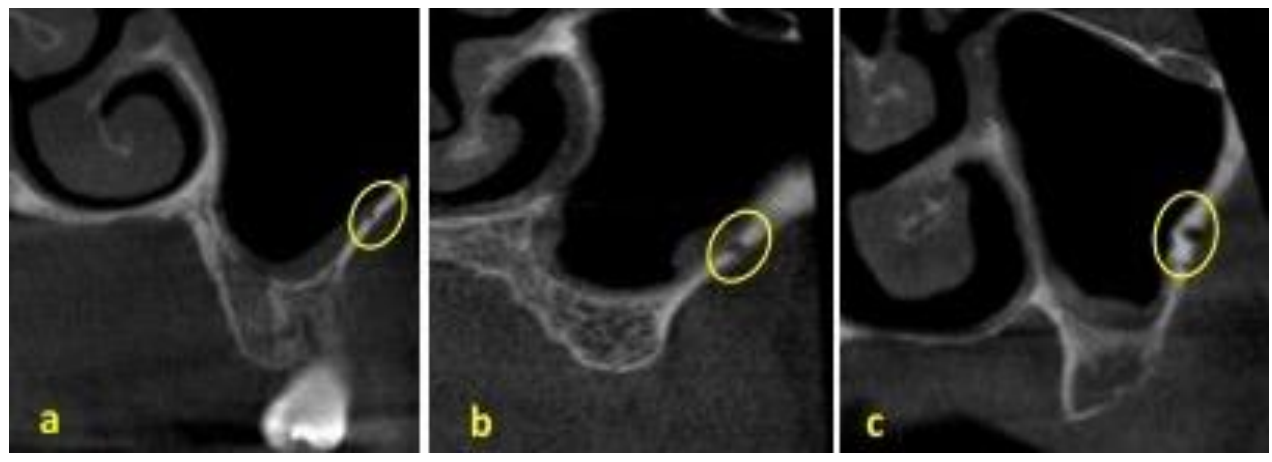

Şekil 2. a) PSAA çapı b) PSAA'nın lateral duvardaki alt noktası ile sinüs tabanı ve alveoler kret tepesi arasındaki izdüşümsel dik mesafeler c) PSAA'nın lateral duvardaki alt noktası ile sinüs tabanı arasındaki oblik mesafe d) PSAA'nın lateral duvardaki alt noktası ile alveoler kret tepesi arasındaki oblik mesafe
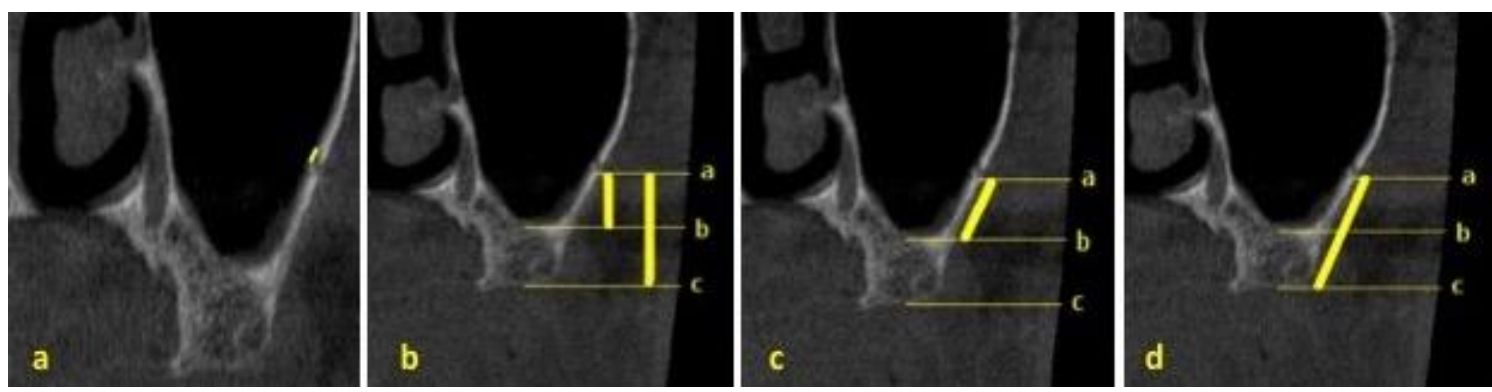

Her hastadan önce kalibre edilmiş dental volumetrik tomografi cihazı (MORITA, Kyoto, Japonya) ile alınmış maksiller sinüs görüntüleri retrospektif olarak çalışmaya dahil edildi. Değerlendirmeye alınan bütün KIBT’ler, 90 kV, 8.0 mA ve 9.4 sn maruz kalma süresinde çalıştırılan cihaz ile alınan volumetrik tomografilerden elde edildi.

Tek bir deneyimli araştırıcı tarafından, kalibrasyon ve gözlem içi güvenirlilik ve tekrarlanabilirliğin belirlenmesi amacı ile ilk ölçümden 2 hafta sonra rastgele seçilmiş 25 hastanın görüntüleri yeniden değerlendirildi. 


\section{İstatistiksel Analiz}

İstatistiksel analizler için SPSS versiyon 22.0 (IBM SPSS Statistics) programı kullanılarak, Ki-kare testi, Student t ve MannWhitney U testleri yapıldı. Normal dağılıma uygunluk Shapiro Wilk testi, normal dağılıma uygun olmayan veriler ise Kruskal Wallis testi kullanılarak karşılaştırıldı. Kategorik veriler Pearson Ki-Kare testi, sürekli değişkenlerin karşılaştırılmasında da Mann-Whitney U veya bağımsız-örneklem t testi kullanıldı. Bağımsız grup sayısı iki olduğunda Student's t testi gruplar arası ortalamalar yönünden farkın önemliliği, Tek Yönlü Varyans Analizi (One-Way ANOVA) ise ikiden fazla grup arasındaki farkın önemliliğini araştırmak için kullanıldı. Sonuçlar ortanca (minimum-maksimum), frekans ve yüzde olarak verildi ve $\mathrm{p}<0,05$ için istatistiksel olarak anlamlı kabul edildi.

Çalışma protokolünün onayı, Yakın Doğu Üniversitesi Bilimsel Araştırmalar Etik Kurulu'ndan (27.02.2020 tarih ve 2020/77/1025 sayı) alındı.

\section{Bulgular}

Çalışmada, 50 hastanın bilateral maksiller sinüs KIBT taramasında toplam 100 sinüs değerlendirildi. Sağ ve sol maksillaların ölçüm değerleri arasında tüm ölçümler için istatistiksel olarak anlamlı bir farklılık bulunmadı ( $p>0,05)$. Bu sonuç göz önüne alınarak, yapılan değerlendirmeler sağ ve sol ayrımı yapılmadan gerçekleştirildi.

Ölçüm yapılan hastalar; dişli, kısmi dişli, dişsiz olarak ayrı ayrı değerlendirildi. Cinsiyet ile diş varlığı açısından istatistiksel olarak anlamlı bir fark bulunamadı $(\mathrm{p}=0,217) . \mathrm{Bu}$ nedenle değerlendirmeler hastaların dişli, kısmi dişli ve dişsiz olmaları göz önüne alınmadan gerçekleştirildi.

PSAA, örneklerin KIBT taramalarının \%10o'ünde tespit edildi.

PSAA'in maxiller sinüs lateral duvarındaki konumu incelendiğinde, istatistiksel olarak kadınlar ve erkekler arasında PSAA konumu açısından anlamlı bir fark olduğu saptandı ( $p=0,005)$. Kadınlarda, PSAA'in daha çok membranın altında yerleştiği (\%56) bulunurken, erkeklerde bu oranın \%34 olduğu saptandı. Kadınlarda PSAA’in lateral sinüs duvarının dış korteksine yakın yerleşimi \%2 olarak bulundu. Buna karşılık lateral sinüs duvarının dış korteksine yakın yerleşme oranı erkeklerde \%20 olarak bulundu (Tablo 1). 
Tablo 1. PSAA konumunun cinsiyete göre dağılımı

\begin{tabular}{|l|c|c|c|c|c|}
\hline \multirow{2}{*}{} & \multicolumn{3}{|c|}{ PSAA konumu } & \multicolumn{1}{|}{} \\
\cline { 2 - 5 } & $\begin{array}{c}\text { İç } \\
\text { (n) }\end{array}$ & $\begin{array}{c}\text { Orta } \\
\text { (n) }\end{array}$ & $\begin{array}{c}\text { D1ş } \\
\text { (n) }\end{array}$ & Toplam & \multirow{2}{*}{ P değeri } \\
\hline $\begin{array}{l}\text { Kadın } \\
\text { Erkek }\end{array}$ & 28 & 21 & 1 & 50 & \multirow{2}{*}{0,005} \\
\cline { 1 - 5 } Toplam & 45 & 23 & 10 & 50 & \multicolumn{1}{|c|}{} \\
\hline
\end{tabular}

PSAA çapları ölçüldü. PSAA kanalının çapı, kortikal sınırların iç tarafları arasındaki en büyük mesafe olarak kaydedildi. Arter birden fazla alanda görülebildiği için kanalın en arka ve en ön konumu arasındaki en büyük değer kanalın çapı olarak kaydedildi. Buna göre, ortalama PSAA çapı 1,07 mm (min. 0,38 mm, max. 1,84 mm) olarak saptandı. PSAA'nın ortalama çapı erkeklerde $1,12 \pm 0,36 \mathrm{~mm}$ ve kadınlarda $1,01 \pm 0,27 \mathrm{~mm}$ idi (Tablo 2).

Tablo 2. PSAA kanal çapları

\begin{tabular}{|l|c|c|c|c|}
\hline & Cinsiyet & $\mathbf{n}$ & Ortalama & Standart sapma \\
\hline PSAA Kanal Çapı & Kadın & 50 & 1,01 & 0,27 \\
& Erkek & 50 & 1,12 & 0,36 \\
\hline
\end{tabular}

Kadınlar ve erkekler arasında PSAA çapları açısından da istatistiksel olarak anlamlı bir fark bulunamadı $(\mathrm{p}=0,234)$. PSAA çaplarının cinsiyet ile karşılaştırması Tablo 3'de gösterilmiştir.

PSAA kanal çapları \%52 hastada 1-2 mm ve \%48 hastada <1 mm idi (Tablo 3).

Tablo 3. Önceden tanımlanmış 2 grupta ayrı ayrı kanal çaplarının yüzdeleri

\begin{tabular}{|l|c|c|c|c|}
\hline \multirow{2}{*}{} & \multicolumn{4}{|c|}{ PSAA Çapları } \\
\cline { 2 - 5 } & $<\mathbf{1 ~ m m}$ & \multicolumn{1}{|c|}{$\mathbf{1 - 2}$ mm } \\
\cline { 2 - 5 } & $\mathrm{n}$ & $\%$ & $\mathrm{n}$ & $\%$ \\
\hline Kadın & 26 & 52 & 24 & 48 \\
\hline Erkek & 22 & 44 & 28 & 56 \\
\hline Toplam & 48 & 48 & 52 & 52 \\
\hline
\end{tabular}


PSAA yerleşimi ile PSAA çapları karşılaştırıldı, istatistiksel olarak anlamlı bir fark gözlenmedi $(\mathrm{p}=0,425)$.

Dişli, kısmen dişli ya da dişsiz olma durumunun da PSAA yerleşimi, çapı ve cinsiyet arasında istatistiksel olarak bir fark yaratmadığı gözlendi ( $p>0,05)$.

PSAA'nın lateral duvardaki alt noktası ile sinüs tabanı ve alveolar kret tepesi arasında ölçülen dik ve oblik mesafeler Tablo 4'de gösterilmiştir.

Tablo 4. PSAA ile kret tepesi ve sinüs tabanı arasındaki mesafeler (mm)

\begin{tabular}{|l|c|c|c|c|}
\hline $\mathrm{n}=100$ & $\begin{array}{c}\text { PSAA } \\
\text { S. Tabanı }\end{array}$ & $\begin{array}{c}\text { PSAA } \\
\text { Kret Tepesi }\end{array}$ & $\begin{array}{c}\text { PSAA } \\
\text { S. Tabanı Oblik }\end{array}$ & $\begin{array}{c}\text { PSAA } \\
\text { K. Tepesi Oblik }\end{array}$ \\
\hline Ortalama & 8,30 & 16,66 & 9,26 & 18,36 \\
\hline Ortanca & 7,68 & 16,07 & 8,70 & 17,71 \\
\hline Minimum & 0,93 & 6,40 & 1,58 & 9,45 \\
\hline Maksimum & 22,07 & 32,91 & 23,44 & 33,62 \\
\hline Standart Sapma & 4,17 & 5,17 & 4,34 & 4,84 \\
\hline
\end{tabular}

PSAA'nın lateral duvardaki alt noktası ile sinüs tabanı ve kret tepesi arasında ölçülen mesafelerin cinsiyet ile ilişkisi değerlendirildi. PSAA'nın alt noktası ile sinüs tabanı arasında dik olarak yapılan ölçümlerdeki mesafe, kadınlarda ortalama 7,60 $\pm 3,68 \mathrm{~mm}$

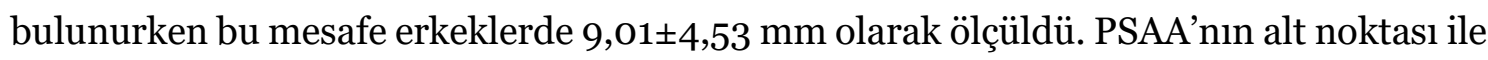

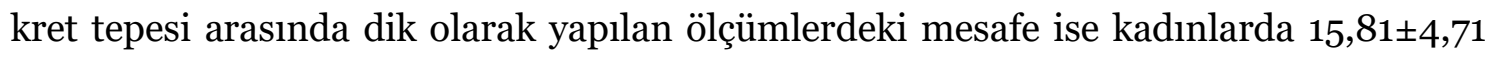
mm, erkeklerde 17,50 $\pm 5,52 \mathrm{~mm}$ olarak bulundu. Bu değerler açısından, kadınlar ile erkekler arasında istatistiksel olarak anlamlı bir fark saptanmadı (sırasıyla, $p=0,09$ ve $\mathrm{p}=0,10$ ) (Tablo 5).

PSAA'nın alt noktası ile sinüs tabanı ve kret tepesi arasındaki oblik mesafeler ölçüldüğünde ise, PSAA alt noktası ile kret tepesi arasındaki oblik mesafe ölçüm değerlerinde cinsiyetler arasında istatistiksel olarak önemli bir fark bulunmazken $(\mathrm{p}=0,07)$, PSAA'nın alt noktası ile sinus tabanı arasındaki oblik mesafe ölçüm değerlerinde erkeklerde kadınlara göre istatistiksel olarak anlamlı yüksek bulunmuştur ( $\mathrm{p}=0,04)$. PSAA'nın lateral duvardaki alt noktası ile sinüs tabanı ve kret tepesi arasında ölçülen dik ve oblik mesafelerin ortalama değerleri Tablo 5’te gösterilmiştir. 
Tablo 5. PSAA lateral duvardaki alt noktası ile sinüs tabanı ve kret tepesi arasında ölçülen mesafelerin cinsiyete göre dağılımı

\begin{tabular}{|l|c|c|c|c|c|}
\hline & Cinsiyet & $\mathbf{n}$ & Ortalama & Standart sapma & p değeri \\
\hline PSAA - S. Tabanı & Kadın & 50 & 7,60 & 3,68 & \multirow{2}{*}{0,091} \\
\cline { 2 - 5 } & Erkek & 50 & 9,01 & 4,53 & \\
\hline PSAA - Kret Tepesi & Kadın & 50 & 15,81 & 4,71 & \multirow{2}{*}{0,104} \\
\cline { 2 - 5 } & Erkek & 50 & 17,50 & 5,52 & \\
\hline PSAA - S. Tabanı Oblik & Kadın & 50 & 8,38 & 3,83 & \multirow{2}{*}{0,041} \\
\cline { 2 - 5 } & Erkek & 50 & 10,15 & 4,67 & \\
\hline PSAA - K. Tepesi Oblik & Kadın & 50 & $\mathbf{1 7 , 4 8}$ & 4,39 & \multirow{2}{*}{0,070} \\
\cline { 2 - 5 } & Erkek & 50 & 19,23 & 5,15 & \\
\hline
\end{tabular}

\section{Tartışma}

Posterior maksillada cerrahi prosedürler için, maksiller sinüslerin anatomik detayları ve olası varyasyonları hakkında detaylı bilgi sahibi olmak gerekir ${ }^{14}$. PSAA ve IOA arasındaki anastomoz, maksiller sinüs membranının, periosteal dokuların ve sinüsün anterolateral duvarının kanlanmasını sağlar. Maksiller sinüs lateral duvarını içeren cerrahi girişimler öncesi bu damarların lokalizasyonu dikkate alınmalıdır³. PSAA, görüş alanını kapatabilecek veya kemik greft materyalinin fiksasyonunu engelleyebilecek kanamaya bağlı olarak maksiller sinüsün lateral duvarında bir kemik pencerenin cerrahi oluşumunu zorlaştırabilir² ${ }^{2}$ Bölgenin anatomisinin iyi bilinmesi tedavi yöntemlerinin başarısı açısından oldukça önemlidir. Bu çalışmada, 50 hastanın sağ ve sol maxiller sinüs (toplam 100 ölçüm) KIBT taramalarını kullanarak PSAA prevalansı, çapları, konumu ve maksiller sinüs tabanı ile alveolar krete olan mesafeleri değerlendirilmiştir.

Ilgüy ve arkadaşları, maksiller sinüste PSAA prevalansını \%89,3 Tehranchi ve ark. \%87, Kim ve ark. \%52, Chitszai ve ark. \%71 bildirmişlerdir ${ }^{13^{-16}}$. Bu çalışmada ise, PSAA kanalının varlığı, incelenen örneklerin \%100'ünde tespit edilmiştir. Bu durum, diğer çalışmaların metodolojisindeki farklılıklar ve PSAA'nın görüntüler üzerindeki örnek boyutu ve tanımlarından kaynaklanıyor olabilir, çünkü Solar ve ark. ile Rosano ve ark. kadavra örneklerinin \%10o'ünde PSAA ve IOA'in endosseöz anastomozunun mevcut olduğunu göstermiştir4,9. Diğer çalışmalarda, sunulan bulgulardan farklı olarak, PSAA'nın KIBT veya CT taramalarında tespit edilememesinin mutlaka olmadığı 
anlamına gelmediğini gösterir. Bu çalışmanın sonuçları, muhtemelen kanalın tüm örneklerde mevcut olduğu ve farklılıkların olası farklı teknik ve cihazların kullanımından, kanalın küçük çapından ve doğru gözlem eksikliğinden kaynaklandığı hipotezini doğrulamaktadır ${ }^{13,14}$.

Güncü ve arkadaşları çalışmalarında ortalama PSAA çapını 1,3 mm, Kim ve ark. 1,52 mm, Tehranchi ve ark. 1,29 mm, Atul ve ark. 0,63 mm, Danesh-Sani ve ark. 1,17 mm, Zhitian ve ark. 0,96 mm, Chitsazi ve ark. ise 1,37 mm bulmuşlardır5,13,14,16-19. Bu çalışmada ise PSAA kanalının ortalama çapı 1,07 mm olup, o,38 $\mathrm{mm}$ ile 1,84 $\mathrm{mm}$ arasında değişmiştir. PSAA'nın görüntülenmesi veya görüntü ayrıntısı, KIBT cihazının voksel boyutu ile sınırlıdır. Voksel boyutu ne kadar küçükse, sinüs duvarındaki veya kemik içindeki arterin çözünürlüğü ve daha iyi ayırt edilebilirliği o kadar yüksek olur². PSAA kanal çaplarının farklılıkları, farklı teknikler ve cihazların kullanımından kaynaklanıyor olabilir.

İlgüy ve ark. PSAA'in \%71,1'inde de arterin intraosseoz konumda bulunduğunu saptamışlardır ${ }^{15}$. Güncü ve ark. da çalışmalarında PSAA'nın \%68,2 oranında, Tehranchi ve ark. \%47 oranında, Chitsazi ve ark. \%73,2 oranında, Danesh-Sani ve ark. da benzer şekilde \%69,6 oranında interosseoz yerleştiğini bulmuşlardır5,13,14,18. Bu çalışmada ise PSAA'nın intraosseoz yerleşimli bulunma sıklığı \%44 bulunmuştur. PSAA'nın intraosseos görülme sıklığı için elde ettiğimiz sonuç Tehranchi ve ark.'nın bir çalışmasındaki değere yakındır.

Ilgüy ve ark. PSAA'nın lokalizasyonu ile cinsiyet arasında da istatistiksel açıdan önemli bir fark bulunduğunu saptamışlardır. PSAA'nın sinus lateral duvarının dışında yerleşiminin ise erkeklerde kadınlara oranla belirgin olarak daha sik olduğunu gözlemişlerdir (sırasıyla \%10 ve \%1,9) ${ }^{15}$. Tehranchi ve arkadaşları ise, PSAA'nın inraosseöz yerleşiminin erkeklerde daha sık olduğunu $(\% 47,9)$, membranın altında yerleşiminin de kadınlarda daha sık olduğunu (\%48) göstermişlerdir ${ }^{13}$. Bu çalışmada ise Ilgüy ve ark.'nın çalışmalarına benzer şekilde lateral duvarın dışında yerleşimin, erkeklerde kadınlara oranla daha sık olduğu (sırasıyla \%20, \%2), Tehranchi ve ark. çalışmalarına benzer şekilde membranın altında yerleşimin de, kadınlarda erkeklere oranla istatistiksel anlamlı olarak yüksek olduğu sonucunu elde edilmiştir (sırasıyla \%56, $\% 34)$. 
PSAA'nın alt sınırından alveolar krete olan ortalama mesafe dik ölçümde 16,66 5 5,17 mm, oblik ölçümde ise 18,36 4,84 mm (kadınlarda dik ölçüm 15,81 \pm 4,71 mm, oblik ölçüm 17,48 \pm 4,39 mm, erkeklerde ise dik ölçüm 17,50 \pm 5,52 mm, oblik ölçüm 19,23 \pm $5,15 \mathrm{~mm}$ ) olarak bulunmuştur ve bu sonuçlar diğer çalışmalarda bildirilen değerlere yakındır. PSAA alt sınırı ile kret tepesi arası oblik mesafe Ilgüy ve ark. tarafından $16,88 \pm 3,46 \mathrm{~mm}$ (kadınlarda 16,79 $\pm 3,79 \mathrm{~mm}$, erkeklerde 17,00 $\pm 2,94 \mathrm{~mm}$ ), Güncü ve ark.

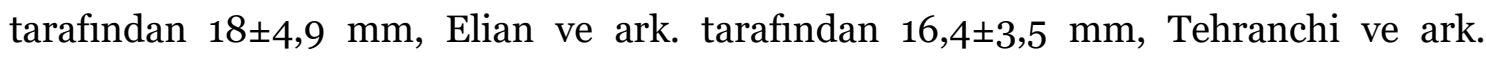

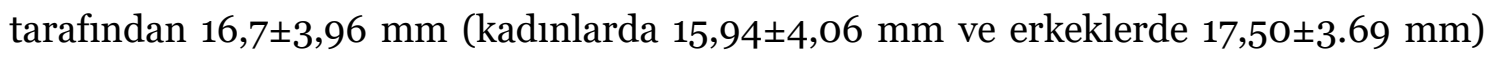
olarak bildirilmiştir5,13,15,20. PSAA alt sınırı ile kret tepesi arası dik mesafe ise Kim ve ark.

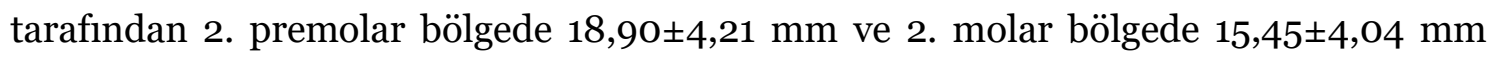
olarak, Kurt ve ark. tarafindan da 2. premolar bölgede $27,60 \pm 5,80 \mathrm{~mm}$ ve 2. molar bölgede 19,50 $\pm 6,20 \mathrm{~mm}$ olarak bildirilmiştir. Sonuçlardaki değişkenlik, bireyler arasında alveolar kretin dikey yüksekliğindeki farklılıklar ile açıklanabilir6,21.

Bu çalışmada, PSAA'nın alt sınırından maksiller sinüs tabanına olan ortalama mesafe dik ölçümde ortalama $8,30 \pm 4,17 \mathrm{~mm}$, oblik ölçümde ise ortalama $9,26 \pm 4,34 \mathrm{~mm}$

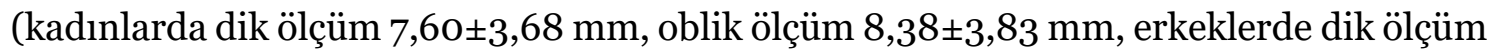

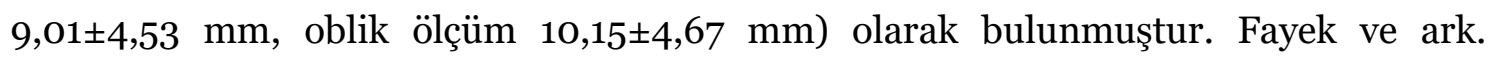
çalışmalarında, PSAA kanalının alt sınırından sinüs tabanına olan ortalama dik mesafeyi

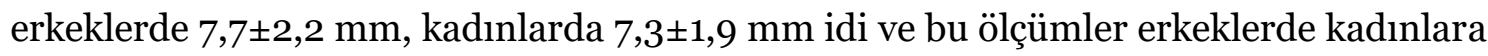
göre bu çalışmadaki bulgularla da uyumlu olarak biraz daha yüksektir. Bu bulgular Güncü ve ark. ve Mardinger ve ark. ile de uyumludur5,22,23.

PSAA'nın alt noktası ile sinus tabanı arasındaki oblik mesafe ölçüm değerlerinde erkeklerde kadınlara göre istatistiksel olarak anlamlı yüksek olması arterlerin pozisyonlarındaki anatomik farklılıklar ile açıklanabilir. Ayrıca, maksiller sinüs hacminin erkeklerde kadınlara göre daha fazla olduğu bildirilmiştir²3,24.

\section{Sonuç}

Diş Hekimliği kliniklerine başvuran hastalarda tedavi planlaması öncesi KIBT görüntülerinin incelenmesi, tedavi planlanırken sonucu etkileyebilecek anatomik oluşumları önceden tespit ederek tedavinin daha başarılı bir şekilde gerçekleştirilmesine olanak sağlayacaktır. Ayrıca, hastanın sağlık durumunu etkileyebilecek diğer 
patolojilerin de saptanması ve ileride oluşabilecek sağlık sorunlarının önüne geçilmesi açısından da önemlidir.

Bunların yanında KIBT, PSAA'nın lokalizasyonunun belirlenmesinde de yardımcı olmaktadır. Kadınlarda PSAA’nın lateral duvarın özellikle iç kısmına, erkeklerde ise dış kısmına yerleşiminin daha sık bulunabileceği göz önünde bulundurulmalıdır. Ayrıca PSAA, konumu ve mesafesi açısından cinsiyetler arasında değişkenlik gösterebilmektedir.

Son yıllarda KIBT taraması mükemmel bir tanı aracı oluşturduğundan birçok prosedür için rutin olarak gerçekleştirilmektedir. Sonuç olarak, KIBT ile preoperatif görüntüleme, membran perforasyonu ve kanama komplikasyonları riskini en aza indirmek ve mümkün olan en iyi tedaviyi sağlamak için maksiller posterior alanlarda cerrahi girişimler, implant yerleştirmeleri veya maksiller sinüs liftlerini planlarken PSAA'nın varlığını, yerini ve çapını değerlendirmede oldukça faydalıdır. Bu nedenle, girişimler öncesi KIBT’lerin bu açılardan titizlikle değerlendirilmesi, tedavi planı ve başarısı açısından büyük önem taşımaktadır.

Çalışma birkaç faktörle sınırlıdır. Sunulan çalışma retrospektif olarak bir dental radyoloji merkezinde yapılmıştır. Aynı bölgede yaşayan küçük bir grupta gerçekleştirildiğinden, sonuçlar genel popülasyonla karşılaştırıldığında yetersiz kalabilir. Üstelik bu çalışmaya sadece yetişkinler dahil edilmekle beraber bu konuda veri eksikliği nedeniyle yaş grubu analizi yapılamamıştır. Bu nedenle daha büyük ve yaygın gruplarda bu çalışmaların tekrarlanması, doğruluk payını yükseltecektir.

\section{KAYNAKLAR}

1. Kalyvas D, Kapsalas A, Paikou S, et al. Thickness of the Schneiderian membrane and its correlation with anatomical structures and demographic parameters using CBCT tomography: a retrospective study. International Journal of Implant Dentistry. 2018;4:32-39.

2. Pandharbale AA, Gadgil RM, Bhoosreddy AR, et al. Evaluation of the posterior superior alveolar artery using cone beam computed tomography. Pol $J$ Radiol. 2016;81:606-610. 
3. Traxler H, Windisch A, Geyerhofer U, et al. Arterial blood supply of the maxillary sinus. Clin Anat. 1999;12(6):417-421.

4. Rosano G, Taschieri S, Gaudy JF, et al. Maxillary sinus vascularization: a cadaveric study. J Craniofac Surg. 2009;20:940-943.

5. Güncü GN, Yildirim YD, Wang HL, et al. Location of posterior superior alveolar artery and evaluation of maxillary sinus anatomy with computerized tomography: a clinical study. Clin Oral Implants Res. 2011;22:1164-1167.

6. Jensen OT, Shulman LB, Block MS, et al. Report of the sinus consensus conference of 1996. International Journal of Oral \& Maxillofacial Implants. 1998;13:11-45.

7. Tong DC, Rioux K, Drangsholt M, et al. A review of survival rates for implants placed in grafted maxillary sinuses using meta-analysis. International Journal of Oral \& Maxillofacial Implants. 1998;13:175-182.

8. Regev E, Smith RA, Perrott DH, et al. Maxillary sinus complications related to endosseous implants. International Journal of Oral \& Maxillofacial Implants. 1995;10:451-461.

9. Solar P, Geyerhofer U, Traxler H, et al. Blood supply to the maxillary sinus relevant to sinus floor elevation procedures. Clinical Oral Implants Research. 1999;10:34-44.

10. Ella B, Sedarat C, Noble Rda C, et al. Vascular connections of the lateral wall of the sinus: surgical effect in sinus augmentation. International Journal of Oral \& Maxillofacial Implants. 2008;23:1047-1052.

11. Monje A, Catena A, Monje F, et al. Maxillary sinus lateral wall thickness and morphologic patterns in the atrophic posterior maxilla. J Periodontol. 2014;85(5):676-682.

12. Shoaleh S, Barbad Z, Shahla MD, et al. Evaluation of anatomic variations in maxillary sinus with the aid of cone beam computed tomography (CBCT) in a population in south of Iran. J Dent (Shiraz). 2016;17(1):7-15. 
13. Tehranchi M, Taleghani F, Shahab S, et al. Prevalence and location of the posterior superior alveolar artery using cone-beam computed tomography. Imaging Sci Dent. 2017;47(1):39-44.

14. Chitsazi MT, Shirmohammadi A, Faramarzi M, et al. Evaluation of the position of the posterior superior alveolar artery in relation to the maxillary sinus using the cone-beam computed tomography scans. J Clin Exp Dent. 2017;9(3):394399.

15. Ilgüy D, Ilgüy M, Dolekoglu S, et al. Evaluation of the posterior superior alveolar artery and the maxillary sinus with CBCT. Braz Oral Res. 2013;27:431-437.

16. Kim JH, Ryu, JS, Kim KD, et al. A Radiographic study of the posterior superior alveolar artery. Implant Dentistry. 2011;20(4):306-331.

17. Atul AP, Rajeev M, Gadgil AR, et al. Evaluation of the posterior superior alveolar artery using cone beam computed tomography. Pol J Radiol. 2016;81:606-610.

18. Danesh-Sani SA, Movahed A, ElChaar ES, et al. Radiographic evaluation of maxillary sinus lateral wall and posterior superior alveolar artery anatomy: A cone-beam computed tomographic study. Clin Implant Dent Relat Res. 2017;19(1):151-160.

19. Zhitian D, Ping Y, Runfa W, et al. Evaluating the bony canal structure of the posterior superior alveolar artery using cone-beam computed tomography. Hua Xi Kou Qiang Yi Xue Za Zhi. 2014;32(6):581-583.

20. Elian N, Wallace S, Cho SC, et al. Distribution of the maxillary artery as it relates to sinus floor augmentation. Int J Oral Maxillofac Implants. 2005;20:784-787.

21. Kurt M, Kurşun E, Alparslan E. Posterior superior alveolar artery evaluation in a Turkish subpopulation using CBCT. Clin Dent Res. 2014;38(2):12-19.

22. Mardinger O, Abba M, Hirshberg A, et al. Prevalence, diameter and course of the maxillary intraosseous vascular canal with relation to sinus augmentation procedure: a radiographic study. Int J Oral Maxillofac Surg. 2007;36:735-738. 
23. Fayek MM, Amer ME, Bakry AM. Evaluation of the posterior superior alveolar artery canal by cone-beam computed tomography in a sample of the Egyptian population. Imaging Sci Dent. 2021;51:e5.

24. Jasim HH, Al-Taei JA. Computed tomographic measurement of maxillary sinus volume and dimension in correlation to the age and gender (comparative study among individuals with dentate and edentulous maxilla). J Bagh Coll Dent. 2013;25:87-93. 